\title{
Predictors of injury from fighting among adolescent males
}

\author{
B J Hammig, L L Dahlberg, M H Swahn
}

\begin{abstract}
Objectives-To identify violence related behaviors associated with injuries among adolescent males involved in fights.

Methods-Data from the National Longitudinal Study of Adolescent Health were used to develop weighted estimates of injury prevalence and associations between injury and violence related behaviors.

Results-Forty seven per cent injured others and $18 \%$ were themselves injured in a fight among adolescent males in the preceding 12 months. Group fighting, fighting with strangers, and weapon use were predictive of injury in this sample.

Conclusions-These findings suggest that injuries associated with fighting are a health risk among adolescent males. Certain behaviors, such as fighting in groups and fighting with strangers, increase the likelihood of injuries requiring medical attention.
\end{abstract}

(Injury Prevention 2001;7:312-315)

Keywords: violence; adolescent behavior

Fighting is an assaultive behavior among adolescents that may lead to an increased risk of injury or death. Recent national estimates from the Youth Risk Behavior Survey in the US indicate that, in $1997,37 \%$ of students in grades $9-12$ had been in a fight within the preceding 12 months. ${ }^{1}$ Over the same period, approximately $4 \%$ reported seeking medical attention for an injury sustained from a fight, and $7 \%$ reported being threatened or injured with a weapon on school property. Males are much more likely than females to be involved in a fight and to be victims and perpetrators of assaults. Nationally, aggravated assault (that is, rape, weapon related assault, or assault with intent to harm) victimization rates among males exceed those among females $(12 / 1000 v 6 / 1000)$, as do arrests for assault $(82 \%$ v $18 \%){ }^{2}$

Although several studies have examined correlates of violent behaviors among youth, ${ }^{3-9}$ few have assessed the association between injury and fighting. ${ }^{3}$ In this study, we examine the associations between violent behaviors such as group fighting, weapon use, and circumstances surrounding fights, and the risk of a fight related injury among a nationally representative sample of adolescent males who reported being in a fight in the past 12 months.

\section{Methods}

We used data from public use tapes of the National Longitudinal Study of Adolescent
Health (NLSAH). The study design and establishment of validity and reliability of the NLSAH have been described in detail elsewhere. ${ }^{10}{ }^{11}$ Briefly, the study used a clustered sampling design of a total of 145 middle, junior, and senior high schools stratified by census region, urbanicity, school type, ethnic composition, and enrollment size, to study a nationally representative sample of public and private school students. ${ }^{1011}$ During the first phase $76 \%$ (90 118) eligible students completed an in-school questionnaire; in the second phase, an in-home survey involved a random sample of 15243 adolescents, stratified by gender and grade level. These students were selected from class rosters of schools that had participated in the first phase of the study. An $80 \%$ response rate was achieved.

The in-home interview obtained information about several health issues including sexuality, substance use, physical activity, nutrition, peer networks, and violence. For personal questions, computer assisted self interviewing (audio-CASI) was incorporated to protect confidentiality and limit parental influence on participant responses. Parental consent and local institutional review board approval were obtained.

The public use data tapes are based on a randomly selected subsample $(n=6504)$ of the original in-home sample. When weighted, the sample is representative of US adolescents in grades $7-12$. Although fighting and injuries are known to occur among females, we restricted our analyses to males because of previous findings of their significantly higher prevalence of fighting. ${ }^{36}$ From this sample in the public use data tapes $(n=3147)$, we analysed from those who reported involvement in a fight within the past 12 months $(n=1314)$.

\section{MEASURES}

From this secondary analysis, we constructed two main outcome variables: being injured and injuring another in a fight in the past 12 months. To measure the number of participants injured themselves, we examined responses to the question: "During the past 12 months, how many times were you in a physical fight in which you were injured and had to be treated by a doctor or nurse?" The number who injured someone else was ascertained by asking "In the past 12 months, how often did you hurt someone badly enough (for them) to need bandages or care from a doctor or nurse?" These outcome variables were dichotomized so that respondents who reported being injured or not in a fight were categorized as "yes," or "no". The same coding scheme was used for injuring another person. 
Table 1 Prevalence of being injured in a fight and injuring others by demographic characteristics $(n=1314)$; values are odds ratios (95\% confidence intervals)

\begin{tabular}{lll}
\hline & $\begin{array}{c}\text { Injured self } \\
(n=242 ; 18.4 \%)\end{array}$ & $\begin{array}{c}\text { Injured another } \\
(n=618 ; 47.0 \%)\end{array}$ \\
\hline $\begin{array}{l}\text { Race } \\
\text { White }\end{array}$ & $17.3(14.3$ to 20.4$)$ & $47.2(43.3$ to 51.2$)$ \\
$\begin{array}{l}\text { Black } \\
\text { Other }\end{array}$ & $22.6(17.1$ to 28.1$)$ & $51.7(45.1$ to 58.3$)$ \\
$\begin{array}{l}\text { Grade level } \\
\text { Middle school }\end{array}$ & $19.1(12.9$ to 25.4$)$ & $41.6(33.9$ to 49.3$)$ \\
$\begin{array}{l}\text { High school } \\
\text { Poverty status } \\
\text { No } \\
\text { Yes }\end{array}$ & $17.8(13.6$ to 22.0$)$ & $42.5(37.2$ to 47.9$)$ \\
& $19.1(16.0$ to 22.1$)$ & $49.5(45.7$ to 53.3$)$ \\
*Defined by parental response to whether or not they received \\
public assistance such as welfare.
\end{tabular}

Other violence related variables assessed included aspects of fighting related behaviors and weapon related behaviors. Fighting related behaviors included group fighting, and where and with whom the person fought most recently. Group fighting was based on responses to the question: "In the past 12 months, how often did you take part in a fight where a group of your friends was against another group?" with responses categorized as "never," " 1 or 2 times", or " 3 or more times". Location of the most recent fight was grouped into two categories: "school" and "elsewhere". Opponents were grouped into three categories: "family/friend/acquaintance", "stranger", and "other" (such as a teacher or employer).

Weapon carrying was determined by the question: "During the past 30 days, on how many days did you carry a weapon - such as a gun, knife or club-to school?" A "yes" response was assigned if they carried any weapon on one or more days. Two questions on weapon related activities were used to measure weapon use and the responses dichotomized as "yes" or "no".

Table 2 Crude odds ratios (95\% confidence intervals) for fighting related injury to self and causing injury to another by violence related behaviors among US males who reported fighting during the past 12 months $(n=1314)$

\begin{tabular}{|c|c|c|}
\hline Variable & Injured self $(n=242)$ & Injured another $(n=618)$ \\
\hline \multicolumn{3}{|l|}{ Group fighting } \\
\hline Never & 1.00 & 1.00 \\
\hline $1-2$ times & $1.15(0.8$ to 1.7$)$ & $3.12(2.3$ to 4.2$)$ \\
\hline 3 or more times & $2.08(1.3$ to 3.3$)$ & $8.59(5.4$ to 13.8$)$ \\
\hline \multicolumn{3}{|l|}{ Fought whom } \\
\hline Family/friend/acquaintance & 1.00 & 1.00 \\
\hline Other & $1.11(0.7$ to 1.7$)$ & $1.52(1.1$ to 2.1$)$ \\
\hline Stranger & $1.85(1.3$ to 2.7$)$ & 2.15 (1.6 to 2.9$)$ \\
\hline \multicolumn{3}{|l|}{ Where fought } \\
\hline School & 1.00 & 1.00 \\
\hline Elsewhere & $0.79(0.6$ to 1.1$)$ & $1.42(1.1$ to 1.9$)$ \\
\hline \multicolumn{3}{|l|}{ Weapon use or threats } \\
\hline No & 1.00 & 1.00 \\
\hline Yes & $2.11(1.4$ to 3.1$)$ & $3.58(2.5$ to 5.2$)$ \\
\hline \multicolumn{3}{|c|}{ Carried a weapon to school past 30 days } \\
\hline No & 1.00 & 1.00 \\
\hline Yes & $1.77(1.2$ to 2.6$)$ & $1.92(1.4$ to 2.7$)$ \\
\hline \multicolumn{3}{|l|}{ Race } \\
\hline White & 1.00 & 1.00 \\
\hline Black & 1.39 (1.0 to 2.0$)$ & $1.19(0.9$ to 1.6$)$ \\
\hline Other & $1.13(0.7$ to 1.8$)$ & $0.79(0.6$ to 1.1$)$ \\
\hline \multicolumn{3}{|l|}{ Grade level } \\
\hline High school & 1.00 & 1.00 \\
\hline Middle school & $1.08(0.8$ to 1.5$)$ & $1.32(1.0$ to 1.7$)$ \\
\hline \multicolumn{3}{|l|}{ Poverty ${ }^{\star}$} \\
\hline No & 1.00 & 1.00 \\
\hline Yes & $1.01(0.6$ to 1.7$)$ & $1.26(0.8$ to 1.9$)$ \\
\hline
\end{tabular}

${ }^{\star}$ Defined by parental response to whether or not they received public assistance such as welfare.
STATISTICAL ANALYSIS

We calculated prevalence estimates for fighting related injuries and bivariate associations between each of the independent variables and the main outcome variables. Crude odds ratios (OR) and 95\% confidence intervals (CI) were also calculated. Two multivariate logistic regression models were created that included variables found to be significant in the bivariate analyses, to assess the independent effects of group fighting, weapon use, weapon carrying, and circumstances of fighting on the risk of injury to self and others. To assess potential multicollinearity between the independent variables, we conducted a Pearson product moment correlation analysis. Correlation coefficients ranged from 0.05 to 0.35 , suggesting that no multicollinearity problems existed. To account for the complex sampling design and to obtain national representation from the study sample, all statistical analyses were calculated on weighted data using the SUDAAN statistical package. ${ }^{12}$

\section{Results}

Of the study sample ( $\mathrm{n}=1314), 59 \%$ were white, $26 \%$ black, and $15 \%$ were categorized as "other". Thirty five per cent of the students were in grade 7 or 8 and $65 \%$ were in grades 9-12. Approximately $10 \%$ were in families receiving public assistance.

Eighteen per cent reported needing medical attention as a result of an injury sustained in a fight in the past 12 months. Prevalence rates of injury were similar for middle and high school students (18\% v 19\%) and were also similar among the different racial and economic groups (table 1). Almost half reported that they had injured someone else badly enough that they needed medical attention-slightly more high school students than middle school students $(50 \% v 42 \%)$.

Results of bivariate logistic regression analyses between injury related variables and violence related variables are presented in table 2. Students who participated in group fighting three or more times were twice as likely (OR = $2.08 ; 95 \%$ CI 1.3 to 3.3 ) to have been injured in a fight than others. Likewise, those who fought with strangers were more likely to have been injured than were students who reported fighting with someone they knew $(\mathrm{OR}=1.85$; $95 \% \mathrm{CI}=1.3$ to 2.7 ). Those who reported using a weapon to threaten or harm someone and those who had carried a weapon to school in the past 30 days were more likely to be injured than those who did not. Students who reported group fighting, fighting with a stranger, or using or carrying a weapon were also more likely to have injured someone else.

The multivariate logistic regression model showed that group fighting three or more times and most recently fighting with a stranger, were each independently associated with having been injured (table 3). Participants who reported that their last fight occurred somewhere other than at school, were less likely to be injured when compared with students involved in a fight at school. Neither weapon 
Table 3 Multivariate logistic regression analysis for fighting related injury to self and causing injury to another by violence related behaviors among US males who reported fighting during the past 12 months; values are adjusted odds ratios * (95\% confidence intervals)

\begin{tabular}{|c|c|c|}
\hline Variable & Injured self $(n=242)$ & Injured another $(n=618)$ \\
\hline \multicolumn{3}{|l|}{ Group fighting } \\
\hline Never & 1.00 & 1.00 \\
\hline $1-2$ times & $1.03(0.7$ to 1.6$)$ & 2.51 ( 1.8 to 3.5$)$ \\
\hline 3 or more times & $1.97(1.1$ to 3.5$)$ & $5.67(3.2$ to 10.0$)$ \\
\hline \multicolumn{3}{|l|}{ Fought whom } \\
\hline Family/friend/acquaintance & 1.00 & 1.00 \\
\hline Other & $0.97(0.6$ to 1.6$)$ & $1.33(0.9$ to 2.0$)$ \\
\hline Stranger & $2.01(1.3$ to 3.1$)$ & $1.69(1.2$ to 2.4$)$ \\
\hline \multicolumn{3}{|l|}{ Where fought } \\
\hline School & 1.00 & 1.00 \\
\hline Elsewhere & $0.66(0.5$ to 1.0$)$ & $1.19(0.9$ to 1.6$)$ \\
\hline \multicolumn{3}{|l|}{ Weapon use or threats } \\
\hline No & 1.00 & 1.00 \\
\hline Yes & $1.33(0.8-2.3)$ & $2.24(1.4$ to 3.7$)$ \\
\hline \multicolumn{3}{|c|}{ Carried a weapon to school past 30 days } \\
\hline No & 1.00 & 1.00 \\
\hline Yes & $1.30(0.8$ to 2.0$)$ & $1.18(0.8$ to 1.8$)$ \\
\hline \multicolumn{3}{|l|}{ Race } \\
\hline White & 1.00 & 1.00 \\
\hline Black & $1.38(0.9$ to 2.1$)$ & $1.05(0.7$ to 1.5$)$ \\
\hline Other & $0.89(0.5$ to 1.6$)$ & $0.64(0.4$ to 1.0$)$ \\
\hline \multicolumn{3}{|l|}{ Grade level } \\
\hline High school & 1.00 & 1.00 \\
\hline Middle school & $1.02(0.7$ to 1.5$)$ & $1.20(0.9$ to 1.7$)$ \\
\hline \multicolumn{3}{|l|}{ Povertyt } \\
\hline No & 1.00 & 1.00 \\
\hline Yes & $0.67(0.4$ to 1.2$)$ & $1.03(0.7$ to 1.6$)$ \\
\hline
\end{tabular}

${ }^{\star}$ Odds ratios are adjusted for all variables shown in the model.

$\dagger$ Defined by parental response to whether or not they received public assistance such as welfare.

carrying nor weapon use was associated with being personally injured. With regard to injuring another person, group fighting, most recently fighting with a stranger, or having used a weapon to harm or threaten someone were each independently significant risk factors.

\section{Discussion}

Several interesting findings are worth noting. Prevalence estimates for fight related injury were higher $(18 \%)$ compared with other national studies. Other studies assessing fight related injury have either included females in their analyses, ${ }^{3}$ or assessed the prevalence of injury among all male adolescents without subsetting out only those who fought. ${ }^{1}$ These differences in sample selection and study design likely account for the higher prevalence found in the current study. Additionally, the use of audio-CASI technology and questioning participants in their home may have made them more willing to answer potentially controversial questions and to do so honestly. We found that the number of group fighting incidents was associated with injury risk-a finding consistent with previous research. ${ }^{3}$ Reasons for this finding cannot be ascertained by the current study, however it may be postulated that persons who fight repeatedly may be more violent than those who do not fight regularly, or they may become more violent as the regularity of their behavior increases.

Fighting with someone unknown was related to both being injured and to having injured another. Although the reasons for this cannot be established in this study, it may be that when male adolescents fight with someone they know, they are less likely to inflict serious injury because they are able to view this person as an individual. Conversely, the adolescent may view a stranger as someone who is less of an equal or someone they will not have to interact with in the future. Therefore, personal, psychological, and legal consequences may not be important as when they fight with someone who is known. This warrants further investigation.

In both the bivariate and multivariate analyses, using a weapon to threaten or harm someone was associated with reported injury to another, though the odds ratio was somewhat stronger in the bivariate analyses. These results highlight the problem of the prevalence of weapon related behaviors among adolescents. Although homicide rates have declined, weapon use, especially use of firearms, continues to contribute to the high rate of homicides among adolescents and young adults in the US. ${ }^{13}{ }^{14}$ Previous data from the National Youth Risk Behavior Survey indicate that approximately $7 \%$ of students were either threatened or injured with a weapon in the 12 months preceding the survey. In addition, weapon carrying among adolescents is relatively high. ${ }^{17}$ Obviously, the involvement of a weapon, particularly a firearm, in the context of a violent altercation increases the risk of a lethal outcome. ${ }^{15}$ Therefore, interventions aimed at preventing firearm related fights are crucial to the prevention of violence related mortality among adolescents. Fighting is a prominent health risk behavior among adolescent males. Many factors contribute to the manner and outcome of a fight. Whereas some fights may be relatively harmless scuffles between friends, others involve risk of serious injury.

We found that certain characteristics of fights increase the risk of injury, such as fighting in groups or fighting with strangers. The influence of peers on adolescent behavior is well documented. Adolescents are much more likely to engage in certain behaviors when their friends encourage and approve of those behaviors. ${ }^{16}$ This is evident with substance use, delinquency, and sexual activity, and may also be true of violence. Prior research indicates that within a peer group, particularly one involved in a behavior such as fighting, individual values and behaviors are over-ridden by the will of the group. ${ }^{17}$ In other words, an individual may act differently in the presence of a group than when alone. This theory may help explain the consequences of group fighting, in which the peer group may influence the level and degree of violence thereby increasing the risk of injury. Moreover, research on seventh graders showing that the prevalence of injuries among fighters is related to the number of combatants in the fight, further supports our findings. ${ }^{18}$

\section{LIMITATIONS}

Several factors limit the interpretations of the results. First, the study is cross sectional, therefore the direction of the relationship cannot be determined. Second, it is based on an in-school population and may not be representative of adolescents who are not in school. Third, the data are based on self reports and are subject to biases known to be associated with self reported data. Adolescents may be inclined to 


\section{Key points}

- Group fighting was an important risk factor both for being injured during a fight and for injuring another person.

- The objective was to identify violence related behaviors associated with injuries among a nationally representative sample of US male adolescents who were involved in a physical fight.

- We found that certain characteristics of fights increase the risk of injury, such as fighting in groups or fighting with strangers.

- By identifying factors associated with fight injuries, prevention programs can better target those persons or situations when injuries are likely to occur.

- Fighting is a prominent health risk behavior among adolescent males. Many factors contribute to the manner and outcome of a fight. Whereas some fights may be relatively harmless scuffles between friends, others involve risk of serious injury.

under-report the severity or number of their injuries if they view being injured as a sign of weakness or not socially desirable. For the same reason, they may overrate the severity of injuries inflicted on another, if they believe this to be socially desirable. Lastly, owing to the small number of students who reported weapon related behaviors, we were unable to separate those who actually used weapons from those who threatened others with weapons.

\section{Implications for prevention}

We must continue to evaluate violence prevention programs. To date, effective intervention strategies have not been well established, but it is likely that aspects of the school, family, and community environment play important parts in these strategies. ${ }^{19}$ This study offers insights into the prevention of fight related injuries among male adolescents. By identifying factors associated with fight injuries, prevention programs can better target those persons or situations when injuries are likely to occur. Continued research may further identify factors associated with fight related injuries, or perhaps the personality characteristics or behaviours that may predict fighting. Continued efforts on the part of the public health community are needed to understand and prevent assaultive injuries among youth in the US and in other countries as well.

Bart Hammig is currently affiliated with Southern Illinois University, 4632 Pulliam Hall 307, Carbondale, IL 62901-4632, USA

1 Centers for Disease Control and Prevention. Youth risk behavior surveillance-United States, 1997. MMWR Morb Mortal Wkly Rep 1998;47(SS-3).

2 Department of Justice, Bureau of Justice Statistics. Sourcebook of criminal justice statistics - 1997. Washington, DC: Office of Justice Programs, Bureau of Justice Statistics, 1998.

3 Lowry R, Powell KE, Kann L, et al. Weapon carrying, physical fighting, and fight related injury among US adolescents. Am f Prev Med 1998;14:122-9.

4 Centers for Disease Control and Prevention. Physical fighting among high school students-United States. MMWR Morb Mortal Wkly Rep 1992;41(6):91-4.

5 Simon TR, Richardson JL, Dent CW, et al. Prospective psychosocial, interpersonal, and behavioral predictors of handgun carrying among adolescents. Am $\mathcal{F}$ Public Health 1998;88:960-3.

6 Valois RF, McKeweon RE. Frequency and correlates of fighting and carrying weapons among public school adolescents. Am f Health Behav 1998;22:8-17.

7 Ellickson P, Saner H, McGuigan K. Profiles of violent youth: substance use and other concurrent problems. Am $\mathcal{F}$ Public Health 1997;87:985-91.

8 Durant RH, Kahn J, Hayden-Beckford P, et al. The association of weapon carrying and fighting on school property and other health risk and problem behaviors among high school students. Arch Pediatr Adolesc Med 1997;151:360-6.

9 Orpinas PK, Basen-Engquist K, Grunbaum J, et al. The co-morbidity of violence-related behaviors with health-risk behaviors in a population of high school students. F Adolesc Health 1995;16:216-25.

10 Resnick MD, Bearman PS, Blum RW, et al. Protecting adolescents from harm: findings from the national longitudinal study of adolescent health. $7 A M A 1997 ; 278: 823-32$.

11 Sieving RE, Beuhring T, Resnick MD, et al. Development of adolescent self-report measures from the national longitudinal study of adolescent health. $\mathcal{F}$ Adolesc Health 2001;28: $73-81$.

12 Shah BV, Barnwell BG, Bieler GS. Sudaan user's manual. Research Triangle Park, NC: Research Triangle Institute, 1995.

13 Centers for Disease Control and Prevention. Fatal firearm injuries in the United States, 1962-1994. Atlanta, GA: CDC,
National Center for Injury Prevention and Control, November 1996.

November 1996.
Shepard D. Strategies to reduce gun violence. Washington, DC: Office of Juvenile Justice and Delinquency Prevention, US Department of Justice, 1999.

15 Sheley JF, McGee ZT, Wright JD. Gun-related violence in and around inner city schools. Am f Dis Child 1992;146: 677-82.

16 Elliot DS. Youth violence: an overview. Boulder, CO: University of Colorado, Center for the Study and Prevention of Violence, 1994: 1-7.

17 Felson R, Liska A, South S, et al. The subculture of violence and delinquency: individual vs school context effects. Social Forces 1994;73:155-73.

18 Malek MK, Chang B, Davis TC. Self-reported characterization of seventh grade students' fights. $\mathcal{F}$ Adolesc Health 1998;23:103-9.

19 Dahlberg LL. Youth violence in the United States major trends, risk factors, and prevention approaches. Am $\mathcal{F}$ Prev Med 1998;14:259-72. 